CLINICAL STUDY

\title{
Lack of association of liver fat with model parameters of $\beta$-cell function in men with impaired glucose tolerance and type 2 diabetes
}

\author{
Maarten E Tushuizen ${ }^{1}$, Mathijs C Bunck ${ }^{1}$, Petra J W Pouwels ${ }^{2}$, Saskia Bontemps ${ }^{1}$, Andrea Mari ${ }^{3}$ \\ and Michaela Diamant ${ }^{1}$ \\ ${ }^{1}$ Department of Endocrinology/Diabetes Centre, ${ }^{2}$ Department of Physics and Medical Technology and ${ }^{3}$ Institute of Biomedical Engineering, \\ National Research Council, I-35127, Padova, Italy \\ (Correspondence should be addressed to M Diamant who is now at Department of Endocrinology/Diabetes Centre, VU University Medical Centre, \\ PO Box 7057, 1007 MB Amsterdam, The Netherlands; Email: m.diamant@vumc.nl)
}

\begin{abstract}
Objective: Hepatic steatosis and obesity are components of the metabolic syndrome and risk factors for developing type 2 diabetes (T2DM). We studied how liver fat and body fat distribution relate to various aspects of $\beta$-cell function.

Methods: In 12 men with T2DM, 10 men with impaired glucose tolerance (IGT), and 14 age- and body mass index-matched controls, we measured body fat distribution and liver fat by magnetic resonance imaging and spectroscopy. An oral glucose tolerance test was performed to calculate insulin secretory rate (ISR) by C-peptide deconvolution, and $\beta$-cell function using a mathematical model that describes ISR as a function of absolute glucose levels (insulin secretory tone and glucose sensitivity), the glucose rate of change (rate sensitivity), and a potentiation factor.

Results: Waist circumference and the various body fat compartments did not differ among groups. IGT had the highest total and late phase insulin secretion $(P<0.001)$, whereas patients had the lowest insulinogenic index adjusted for insulin resistance $(P=0.006)$. In spite of the hypersecretion, IGT had $\beta$-cell glucose sensitivity, rate sensitivity, and potentiation similar to controls. Liver fat content was highest in diabetic patients $(P=0.004)$ and showed the strongest association with total and late phase of insulin secretion in the IGT group $(r=0.657, P=0.039$ and $r=0.732, P=0.016$ respectively). Model $\beta$-cell function variables showed no association with liver fat or body fat compartments. Conclusions: These data suggest that, in spite of the association of central adiposity and liver fat with T2DM risk, additional, hitherto unknown factors may contribute to $\beta$-cell dysfunction in susceptible humans.
\end{abstract}

European Journal of Endocrinology 159 251-257

\section{Introduction}

Central adiposity and liver steatosis are considered key features underlying the insulin resistance or metabolic syndrome and its associated cardiometabolic abnormalities (1). Furthermore, central obesity and liver steatosis are associated with a high risk for the development of type 2 diabetes (T2DM) $(1,2)$. However, evidence indicates that T2DM only develops in insulin-resistant subjects with the onset of $\beta$-cell dysfunction (3-5). In addition, recent data from the Relationship between Insulin Sensitivity and Cardiovascular risk (RISC) study demonstrate that each of obesity, insulin resistance, abdominal obesity, and insulin response can be found in isolation despite their strong tendency to cluster (6). The relationship of insulin sensitivity and $\beta$-cell function is therefore not unequivocal, confirming the notion that T2DM is a heterogeneous disease. Thus, the mechanisms that link central obesity and liver fat content to $\beta$-cell dysfunction are at present incompletely understood. Chronic exposure of pancreatic islets to high circulating levels of non-esterified fatty acids (NEFA), due to unsuppressed lipolysis in insulin-resistant adipose tissue, is considered as a potential primary cause of $\beta$-cell dysfunction (4). Recently, we reported that fat localized in the pancreas was inversely associated with dynamic measures of $\beta$-cell function in non-diabetic men (7). Previous reports described an association of intra-abdominal fat with $\beta$-cell function $(8,9)$; however, this was not confirmed by others (10-12). This seeming discrepancy may be due to the differences in populations studied and the methods by which $\beta$-cell function parameters were estimated. In particular, if the magnitude of the insulin secretory response to acute glucose stimulation is used to estimate $\beta$-cell function, an association with visceral adipose tissue (VAT) may rather reflect impaired insulin sensitivity (11). Similarly, although liver steatosis is associated with hepatic insulin resistance and inflammation, and was 
shown to predict T2DM in many different populations $(1,2)$, its relation with $\beta$-cell dysfunction is unclear. Insulin-resistant subjects with liver steatosis, when compared with insulin-sensitive individuals, have greater insulin responses and lower hepatic insulin clearance, leading to hyperinsulinemia $(4,13)$.

However, at present, it is unknown whether liver fat contributes to abnormalities in dynamic aspects of $\beta$-cell function that can be derived from a physiological model, describing the relationship between insulin secretion and glucose concentration $(6,14,15)$. Therefore, we assessed liver fat and various aspects of $\beta$-cell function, by performing proton magnetic resonance spectroscopy $\left({ }^{1} \mathrm{H}-\mathrm{MRS}\right)$ measurements and a modified oral glucose tolerance test (OGTT) respectively, in men with normal (NGT) and impaired glucose tolerance (IGT) and in men with uncomplicated T2DM.

\section{Subjects and methods}

\section{Subjects}

After obtaining written informed consent, 36 Caucasian males, aged 35-65 years, with known T2DM $(n=12)$, IGT $(n=10)$, and with NGT $(n=14)$ were studied. Patients were treated by diet $(n=3)$, sulfonylurea (SU; $n=3)$, and/or metformin $(n=6)$ only. Claustrophobia, excess alcohol intake ( $>20$ units/week), history of hepatitis and/or pancreatitis, abnormal liver and renal function tests ( $>2$ times upper limits of normal), recent $(<3$ months) changes in weight $(\geq 5 \%)$ and/or medication, history or current use of steroids, and insulin and/or thiazolidinediones, were exclusion criteria. The local ethics committee approved the study and the investigation conformed to the principles outlined in the Declaration of Helsinki.

\section{Study protocol}

Following an overnight fast, participants arrived at the research centre in the early morning and underwent MR examinations and an OGTT during one single visit. They were instructed to omit their medication in the morning of the examination and to refrain from heavy physical activities during the previous $24 \mathrm{~h}$.

MR examinations, both imaging (MRI) for quantification of abdominal fat compartments and ${ }^{1} \mathrm{H}-\mathrm{MRS}$ to assess liver fat content, were performed in the supine position using a $1.5 \mathrm{~T}$ whole-body system (Sonata; Siemens, Erlangen, Germany). For ${ }^{1} \mathrm{H}-\mathrm{MRS}$, the body array coil was positioned at the upper abdominal region as described previously (7). Briefly, three volumesof-interest in the liver (right anterior, right posterior, and medial or left anterior) of $15 \mathrm{cc}\left(2.5 \times 2.5 \times 2.5 \mathrm{~cm}^{3}\right)$ were measured with stimulated-echo acquisition mode (STEAM) (repetition time $5000 \mathrm{~ms}$, echo time $20 \mathrm{~ms}, 8$ separate acquisitions), avoiding major blood vessels, intra-hepatic bile ducts, and the lateral margin of the liver. Spectral quantification was performed with LCModel (version 6.1) (16). Lipid content is expressed as the percentage of the area under the methyl $(0.9 \mathrm{ppm})$ and methylene peaks $(1.3 \mathrm{ppm})$ relative to that under the water peak $(4.65 \mathrm{ppm})$. Mean lipid content of three volumes-of-interest was used. The coefficient of variation of liver fat in two subsequent MRS sessions, determined in eight subjects, was $4.7 \%$.

VAT area and subcutaneous abdominal adipose tissue area (SAT) were measured by MRI as described previously (17). Briefly, sagittal and coronal slices were used to localize anatomic sites for image acquisition (L4-L5). Three transverse images (spacing, $20 \mathrm{~mm}$ ) were obtained. Quantification of visceral and s.c. fat areas was performed using an image analysis program, running on a Sparc10 workstation (Sun Microsystems, Palo Alto, CA, USA). A seed point is placed in a fat depot, and using a seed-growing procedure, this fat depot can be circumscribed by the selection of a pixel intensity range. The areas were expressed in $\mathrm{cm}^{2}$ and the average area of the three transverse images was used for statistical analyses. Processing of MRI data and calculations of VAT and SAT were performed using a single experienced investigator (S B).

Following the MR examination, a $75 \mathrm{~g}$ OGTT was performed $(14,15)$. Whole blood samples were drawn at $0,10,20,30,60,90$, and 120 min to measure glucose (YSI 2300 STAT Plus Glucose Analyzer, Yellow Springs, Ohio, USA), serum C-peptide, and insulin concentrations (both by IRMA (Centaur, Bayer Diagnostics)). Baseline plasma glucose concentrations were measured by hexokinase-based technique (Roche Diagnostics). HbAlc was measured with cation exchange chromatography (Menarini Diagnostics, Florence, Italy; reference values 4.3-6.1\%). Plasma total cholesterol, high-density lipoprotein cholesterol (HDL-C), and triglycerides were determined by enzymatic methods (Modular, Hitachi). Low-density lipoprotein cholesterol was calculated by the Friedewald formula. NEFA were assessed by enzymatic colorimetric method (WAKO chemicals, Neuss, Germany).

\section{$\beta$-cell function parameters}

Various $\beta$-cell function parameters were calculated. Insulin secretion rates (ISR) were determined from C-peptide deconvolution (18), since hepatic insulin resistance may influence the hepatic clearance of insulin and the clearance of C-peptide is liver independent. The insulinogenic index was calculated as the insulin increment at $30 \mathrm{~min}$ above basal divided by the corresponding glucose increment, without and with subsequent adjustment for homeostasis model assessment (19) insulin resistance $\left(\Delta I_{0-30} / \Delta G_{0-30}\right.$ and $\Delta I_{0-30} /$ $\Delta G_{0-30} /$ HOMA-IR) (14). An oral glucose insulin sensitivity (OGIS) index was derived from OGTT glucose and insulin values and has been demonstrated to give a very 
similar assessment of insulin sensitivity in type 2 diabetic subjects as the glucose clamp (20). Early and late phase ISR were calculated as the ISR integrals from 0 to $30 \mathrm{~min}$ (ISR $\mathrm{AUC}_{0-30}$ ) and 30 to $120 \mathrm{~min}$ (ISR $\mathrm{AUC}_{30-120}$ ) respectively. Dynamic aspects of $\beta$-cell function were assessed using a model describing the relationship between insulin secretion and glucose concentration, which has been detailed previously $(7,14,15)$. In particular, $\beta$-cell glucose sensitivity (i.e., the slope of the dose-response function relating ISR to glucose concentration), ISR at a reference (close to basal) glucose level (calculated from the $\beta$-cell dose-response), and parameters quantifying the ability of the $\beta$-cell to anticipate a phase of rising insulin secretion (or rate sensitivity) and to memorize the glucose stimulus as well as reading incretin signals (potentiation) were calculated.

\section{Modeling of $\boldsymbol{\beta}$-cell function parameters}

The model consists of three blocks: a) a model for fitting the glucose concentration profile, the purpose of which is to smooth and interpolate plasma glucose concentrations; b) a model describing the dependence of insulin (or C-peptide) secretion on glucose concentrations; and c) a model of $\mathrm{C}$-peptide kinetics, i.e. the two-exponential model proposed by Van Cauter et al. (18), in which the model parameters are individually adjusted to the subject's anthropometric data.

The model expresses insulin secretion as the sum of two components. The first component represents the relationship between insulin secretion and absolute glucose concentration at any time point, i.e. a doseresponse function. The mean slope of the dose-response function is taken to represent $\beta$-cell glucose sensitivity. Insulin secretion at reference glucose levels representing the average basal glucose concentration $(5 \mathrm{mmol} / \mathrm{l}$ in non-diabetic and $7 \mathrm{mmol} / \mathrm{l}$ in diabetic subjects) was calculated from the $\beta$-cell dose-response. The doseresponse function is modulated by a time-varying factor, expressing a relative potentiation effect on insulin secretion. The potentiation factor, which encompasses various potentiating signals (glucose-induced potentiation, incretins, neural factors), was set to have a mean value equal to unity over the $2 \mathrm{~h}$ of the study. As the potentiation factor typically increases during an OGTT, the ratio between the potentiation factor value at $2 \mathrm{~h}$ and that at time 0 was used as a parameter quantifying potentiation. The second insulin secretion component represents a dynamic dependence of insulin secretion on the rate of change of glucose concentration. It is proportional to the time derivative of glucose concentration when glucose rises and is zero otherwise. The proportionality constant, termed rate sensitivity, accounts for anticipation of insulin secretion as glucose levels rise. The potentiation factor and total insulin secretion (expressed in $\mathrm{pmol} / \mathrm{min}$ per square meter of body surface area) were calculated every $5 \mathrm{~min}$ for the whole 2-h period, as detailed $(14,15)$.

\section{Statistical analysis}

Results are presented as the means \pm s.E.M. or medians (interquartile range, IQR). Non-normally distributed data were log transformed. Differences between groups were calculated by ANOVA. The association of liver fat content and body fat compartments with variables of $\beta$-cell function was assessed by univariate correlation. We performed regression analysis to assess the association of $\beta$-cell function parameters and liver fat content, adjusting for OGIS alone, and in combination with body mass index (BMI) and age. All statistical analyses were run on SPSS for Windows version 15.0 (SPSS, Chicago, IL, USA). A $P<0.05$ was considered statistically significant.

Table 1 Baseline characteristics of the study population.

\begin{tabular}{|c|c|c|c|c|}
\hline & T2DM & IGT & Controls & $\boldsymbol{P}$ \\
\hline$N$ & 12 & 10 & 14 & - \\
\hline Age (years) & $54.6 \pm 2$ & $58.0 \pm 2$ & $53.6 \pm 3$ & NS \\
\hline $\mathrm{BMI}\left(\mathrm{kg} / \mathrm{m}^{2}\right)$ & $31.3 \pm 1$ & $29.0 \pm 1$ & $29.2 \pm 1$ & NS \\
\hline Waist $(\mathrm{cm})$ & $111.8 \pm 2$ & $107.0 \pm 2$ & $106.2 \pm 3$ & NS \\
\hline Systolic blood pressure $(\mathrm{mmHg})$ & $136 \pm \overline{4}$ & $140 \pm \overline{5}$ & $123 \pm \overline{3}$ & 0.01 \\
\hline Diastolic blood pressure $(\mathrm{mmHg})$ & $82 \pm 2$ & $84 \pm 3$ & $77 \pm 2$ & NS \\
\hline Fasting plasma glucose (mmol/l) & $8.2 \pm 0.5$ & $5.6 \pm 0.2$ & $5.3 \pm 0.1$ & $<0.001$ \\
\hline HOMA-IR & $2.0 \pm 0.3$ & $1.2 \pm 0.1$ & $0.9 \pm 0.1$ & $<0.01$ \\
\hline OGIS $\left(\mathrm{ml} / \mathrm{min} / \mathrm{m}^{2}\right)$ & $328 \pm 12$ & $383 \pm 17$ & $458 \pm 10$ & $<0.001$ \\
\hline $\mathrm{NEFA}(\mathrm{mmol} / \mathrm{l})$ & $0.68 \pm 0.08$ & $0.69 \pm 0.06$ & $0.55 \pm 0.05$ & NS \\
\hline Total-cholesterol (mmol/l) & $4.7 \pm 0.3$ & $5.3 \pm 0.2$ & $4.9 \pm 0.2$ & NS \\
\hline $\mathrm{HDL}-\mathrm{C}(\mathrm{mmol} / \mathrm{l})$ & $1.0 \overline{5} \pm 0.1$ & $1.26 \pm 0.1$ & $1.4 \overline{4} \pm 0.1$ & $<0.01$ \\
\hline LDL-C (mmol/l) & $2.8 \pm 0.3$ & $3.5 \pm 0.2$ & $2.9 \pm 0.2$ & NS \\
\hline Triglycerides (mmol/l) & $2.4 \pm 0.5$ & $1.3 \pm 0.2$ & $1.2 \pm 0.1$ & $<0.01$ \\
\hline
\end{tabular}

Values are mean \pm S.E.M. or median (interquartile range). T2DM, type 2 diabetes mellitus; IGT, impaired glucose tolerance; BMI, body mass index; HOMA-IR, homeostasis model assessment of insulin resistance; OGIS, oral glucose insulin sensitivity; NEFA, non-esterified fatty acids; HDL-C, HDL-cholesterol; LDL-C, LDL-cholesterol; ALT, alanine aminotransferase. 


\section{Results}

Table 1 lists the baseline characteristics of the three groups, which were well matched for age, BMI, and waist circumference. As expected, patients had the highest $\mathrm{HbA1c}$, fasting plasma glucose, triglyceride levels, and HOMA-IR, whereas HDL-C levels and OGIS were lowest. Median liver fat content was highest in patients versus controls, whereas men with IGT had intermediate values (T2DM: 16.6 (IQR 9.7-29.8), IGT: 9.3 (6.9-21.3), NGT: 5.4 (1.8-10.8), $P=0.004$; Fig. 1). Interestingly, VAT and SAT did not differ among patients, IGT and NGT (VAT: $301 \pm 31,263 \pm 20,255 \pm 28 \mathrm{~cm}^{2} ; P=0.454$; SAT: $312 \pm 32,291 \pm 2, \quad 305 \pm 37 ; P=0.899 ; \mathrm{VAT} / \mathrm{SAT}$ ratio: $1.1 \pm 0.1,0.9 \pm 0.1,0.9 \pm 0.1 ; P=0.639)$. In diabetic, when compared with non-diabetic individuals, empirical and model-derived parameters of $\beta$-cell function were significantly impaired (Table 2). IGT had the highest total and late phase insulin secretion $(P<0.001)$, whereas patients, relative to IGT and NGT, had the lowest insulinogenic index adjusted for insulin resistance $(11 \pm 3,82 \pm 14$, and $110 \pm 30 ; P=0.006)$. In spite of the hypersecretion, IGT had $\beta$-cell glucose sensitivity, rate sensitivity, and potentiation similar to controls (Table 2). The model-derived $\beta$-cell parameters did not differ between SU and non-SU users.

In univariate analysis, initially performed in the entire population, liver fat was significantly associated with HOMA-IR $(r=0.459 ; P=0.005)$, OGIS $(r=-0.648$; $P<0.001)$, and VAT $(r=0.359 ; P=0.034)$. Liver fat content showed the strongest association with total and late phase of insulin secretion in the IGT group (Table 3); however, model-derived $\beta$-cell function variables showed no association with liver fat or with VAT or SAT. This lack of association remained after adjustment for OGIS alone and in combination with age and BMI (data not shown).

\section{Discussion}

These data confirm observations by others, who found no association of abdominal fat with dynamic aspects of $\beta$-cell function (10), and extend these findings by showing the absence of a relationship between liver fat content and dynamic $\beta$-cell function variables in men with IGT, T2DM, and age- and BMI-matched NGT controls. An association was present between liver fat and exaggerated and prolonged secretion of insulin after a glucose load, which may in part reflect a measure of $\beta$-cell function, but should rather be regarded as an indicator of impaired insulin sensitivity $(13,21)$. Previous studies found insulin hypersecretion in obese, relative to lean individuals, whereas dynamic $\beta$-cell function parameters were comparable in obese and lean subjects (22). Lifestyle interventions leading to the reduction of VAT in glucose intolerant subjects did not result in improvement of $\beta$-cell function (23). Similarly, weight loss after lifestyle changes in obese women was associated with a decrease in VAT, SAT, and liver fat and with reduced fasting hyperinsulinemia (24). The changes in liver fat and abdominal fat depots were unrelated and confirmed the observations showing that local fat accumulation, including the liver, may be different in people with similar BMI and waist circumference. Adipose tissue-derived proinflammatory adipokines and NEFA have been proposed to link (central) obesity to T2DM by inducing pancreatic islet dysfunction through inflammation and lipotoxicity respectively $(13,25)$. However, the association of inflammatory markers and incident T2DM is not unequivocal $(26,27)$, indicating a more complex interplay among genetic susceptibility, obesity, and $\beta$-cell dysfunction.

The association of hepatic steatosis, as estimated by ALT, and the risk of T2DM were reported by some $(28-30)$, but were not found by us and others $(31,32)$. Theoretically, there are several mechanisms by which fatty liver could indirectly contribute to $\beta$-cell dysfunction, including the recently reported induction of proinflammatory genes in steatotic versus nonsteatotic livers (33), by glucose-lipotoxicity, due to unsuppressed hepatic glucose production and output of triglyceride-rich lipoproteins and oxidative stress injury $(4,32)$. Previously, we showed that pancreatic fat

A
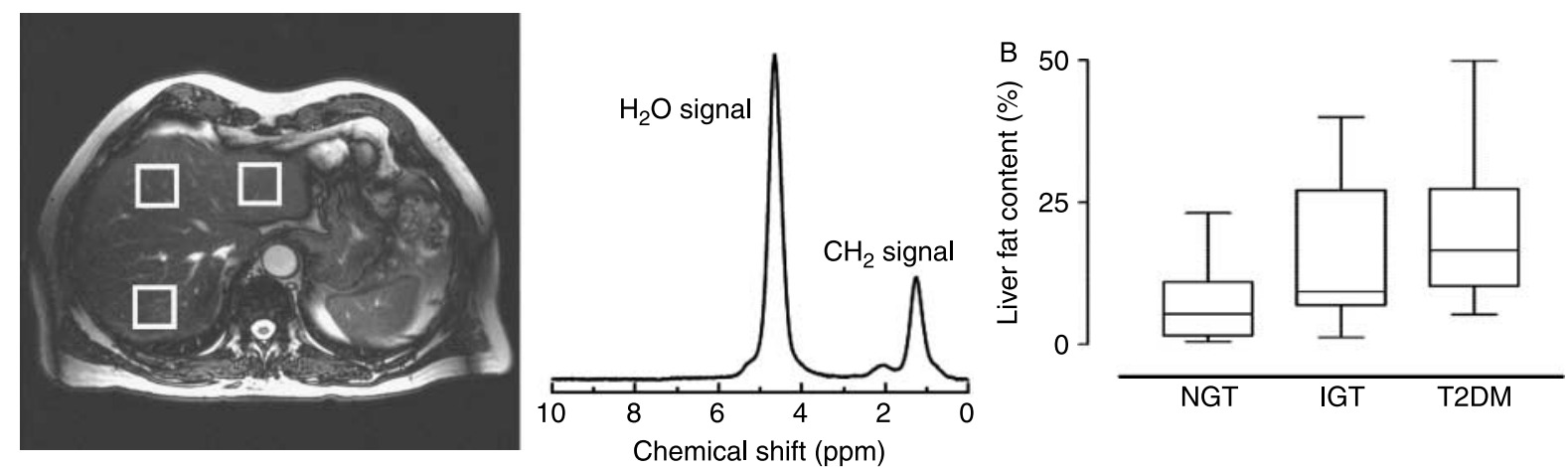

Figure $1(\mathrm{~A}){ }^{1} \mathrm{H}-\mathrm{MR}$ spectra $\left(\mathrm{CH}_{2}\right.$ peak at $1.3 \mathrm{ppm}$ is main signal of lipids) were obtained from abdominal MRI scans indicating volumeof-interest in the liver. (B) Median (interquartile range) lipid content of the liver in men with normal (NGT), in those with impaired glucose tolerance (IGT), and in men with type 2 diabetes (T2DM). 
Table 2 Characteristics of $\beta$-cell function parameters.

\begin{tabular}{|c|c|c|c|c|}
\hline & \multicolumn{3}{|c|}{ Non-T2DM subjects } & \multirow[b]{2}{*}{ T2DM subjects } \\
\hline & & NGT subjects & IGT subjects & \\
\hline \multicolumn{5}{|l|}{ Empirical parameters of $\beta$-cell function } \\
\hline Insulinogenic index $\left(\Delta I_{0-30} / \Delta G_{0-30}\right)$ & $152 \pm 25$ & $148 \pm 38$ & $158 \pm 28$ & $34 \pm 8^{\star}$ \\
\hline Early phase insulin secretion $\left(\mathrm{nmol} / \mathrm{m}^{2}\right)$ & $8.9 \pm 0.7$ & $8.0 \pm 0.8$ & $10.3 \pm 1.1$ & $5.3 \pm 0.4^{\dagger}$ \\
\hline Late phase insulin secretion $\left(\mathrm{nmol} / \mathrm{m}^{2}\right)^{\prime}$ & $40.1 \pm 3.5$ & $30.3 \pm 2.8$ & $53.9 \pm 4.5$ & $28 . \overline{1} \pm 2.6^{\dagger}$ \\
\hline Total insulin secretion $\left(\mathrm{nmol} / \mathrm{m}^{2}\right)$ & $49.0 \pm 3.7$ & $38.2 \pm 3.1$ & $64.2 \pm 4.8$ & $33.4 \pm 2.8^{\dagger}$ \\
\hline \multicolumn{5}{|l|}{ Model parameters of $\beta$-cell function } \\
\hline $\begin{array}{l}\text { Insulin secretion at the reference glucose level } \\
\left(\mathrm{pmol} / \mathrm{min} / \mathrm{m}^{2}\right)^{\mathrm{a}}\end{array}$ & $161 \pm 18$ & $178 \pm 30$ & $138 \pm 13$ & $124 \pm 13$ \\
\hline$\beta$-cell glucose sensitivity $\left(\mathrm{pmol} / \mathrm{min} / \mathrm{m}^{2} / \mathrm{mM}\right)$ & $122 \pm 15$ & $125 \pm 24$ & $118 \pm 14$ & $30 \pm 3^{\star}$ \\
\hline Rate sensitivity $\left(\mathrm{pmol} / \mathrm{m}^{2} / \mathrm{mM}\right)$ & $1107 \pm 131$ & $926 \pm 120$ & $1341 \pm 245$ & $194 \pm 42^{\dagger}$ \\
\hline Potentiation factor & $1.5 \pm \overline{0} .2$ & $1.6 \pm 0.3$ & $1.5 \pm \overline{0} .3$ & $1.0 \pm 0.1$ \\
\hline
\end{tabular}

For calculations of the various $\beta$-cell parameters, see Subjects and methods. Values for $\beta$-cell parameters are mean \pm s.E.M. ${ }^{\star} P<0.01 ;{ }^{\dagger} P<0.001$ (calculated by ANOVA between NGT, IGT, and T2DM groups). NGT, normal glucose tolerance; IGT, impaired glucose tolerance; T2DM, type 2 diabetes mellitus. aparameter calculated at 5 and $7 \mathrm{mmol} / \mathrm{l}$ glucose for non-T2DM and T2DM respectively.

content was an independent determinant of abnormal model parameters of $\beta$-cell function in non-diabetic men (7). In view of the absence of an association of these $\beta$-cell function measures and other fat depots, it seems that fat accumulation in close vicinity to the islets, acting through locally released NEFA and adipokines, may be the culprit in causing $\beta$-cell dysfunction, rather than more distant fat depots (7). Genetic and environmental aspects as well as factors determining the rate of fat accumulation and local fatty replacement in the various organs may contribute to the individual differences in local fat deposition and the differential susceptibility to develop $\beta$-cell dysfunction. Accordingly, once T2DM develops the rate of $\beta$-cell function decline during the course of disease may be unpredictable due to the individual susceptibility of $\beta$-cells to diabetes-related hyperglycemia and its sequelae, including oxidative stress, inflammation, and endothelial dysfunction.

Although the relatively small size of this study may be regarded as a limitation and therefore may not be generalized, the limited number of subjects was sufficient to detect relevant findings such as the significant difference in liver fat between the groups as well as a significant association of liver fat and estimates of insulin resistance.

We conclude that, in spite of the reported association of central adiposity and liver fat with T2DM risk, we found no association of liver fat content or abdominal fat depots, with dynamic $\beta$-cell function parameter

Table $3 \beta$-cell function parameters and their univariate correlation with liver fat.

\begin{tabular}{|c|c|c|c|c|c|c|c|c|c|c|}
\hline & \multicolumn{10}{|c|}{ Liver fat content (log \%) } \\
\hline & & & & & Non-T2DI & M subjec & & & & \\
\hline & \multicolumn{2}{|c|}{ All subjects } & \multirow[b]{2}{*}{$R$} & \multirow[b]{2}{*}{$P$} & \multicolumn{2}{|c|}{ NGT subjects } & \multicolumn{2}{|c|}{ IGT subjects } & \multicolumn{2}{|c|}{ T2DM subjects } \\
\hline & $R$ & $P$ & & & $R$ & $P$ & $R$ & $P$ & $R$ & $P$ \\
\hline \multicolumn{11}{|l|}{ Empirical parameters of $\beta$-cell function } \\
\hline Insulinogenic index $\left(\Delta I_{0-30} / \Delta G_{0-30}\right)$ & -0.243 & NS & -0.039 & NS & -0.045 & NS & -0.101 & NS & -0.033 & NS \\
\hline $\begin{array}{l}\text { Early phase insulin secretion } \\
\left(\mathrm{nmol} / \mathrm{m}^{2}\right)\end{array}$ & -0.121 & NS & 0.102 & NS & 0.048 & NS & -0.159 & NS & 0.498 & NS \\
\hline $\begin{array}{l}\text { Late phase insulin secretion } \\
\left(\mathrm{nmol} / \mathrm{m}^{2}\right)\end{array}$ & 0.381 & 0.022 & 0.668 & $<0.001$ & 0.556 & 0.039 & 0.732 & 0.016 & 0.477 & NS \\
\hline Total insulin secretion $\left(\mathrm{nmol} / \mathrm{m}^{2}\right)$ & 0.318 & NS & 0.634 & 0.001 & 0.525 & NS & 0.657 & 0.039 & 0.494 & NS \\
\hline \multicolumn{11}{|c|}{ Model parameters of $\beta$-cell function } \\
\hline $\begin{array}{l}\text { Insulin secretion at the reference } \\
\text { glucose level }\left(\mathrm{pmol} / \mathrm{min} / \mathrm{m}^{2}\right)^{\mathrm{a}}\end{array}$ & $N A^{b}$ & $N A^{b}$ & -0.019 & NS & 0.007 & NS & 0.375 & NS & 0.159 & NS \\
\hline $\begin{array}{l}\beta \text {-cell glucose sensitivity } \\
\left(\mathrm{pmol} / \mathrm{min} / \mathrm{m}^{2} / \mathrm{mM}\right)\end{array}$ & -0.187 & NS & 0.102 & NS & 0.071 & NS & 0.355 & NS & 0.087 & NS \\
\hline Rate sensitivity $\left(\mathrm{pmol} / \mathrm{m}^{2} / \mathrm{mM}\right)$ & -0.274 & NS & -0.003 & NS & -0.404 & NS & 0.089 & NS & 0.008 & NS \\
\hline Potentiation factor & -0.111 & NS & -0.014 & NS & -0.035 & NS & 0.114 & NS & -0.264 & NS \\
\hline
\end{tabular}

NGT, normal glucose tolerance; IGT, impaired glucose tolerance; T2DM, type 2 diabetes mellitus; NA, not applicable, because of different reference glucose level; $R$, Pearson's correlation coefficient, and only significant correlations are in bold; NS, non significant.

${ }^{a}$ Parameter calculated at 5 and $7 \mathrm{mmol} / \mathrm{l}$ glucose for non-DM2 and T2DM respectively.

${ }^{\mathrm{b}} \mathrm{Not}$ comparable with control subjects because of different reference glucose level. 
variables in men with IGT, T2DM, and age- and BMImatched NGT controls. Thus, additional, hitherto unknown factors may contribute to $\beta$-cell dysfunction in susceptible humans, which require further study.

\section{Acknowledgements}

This work was supported by a grant from the Dutch Diabetes Research Foundation (grant no. 2000.00.025).

\section{References}

1 Kotronen A \& Yki-Järvinen H. Fatty liver: a novel component of the metabolic syndrome. Arteriosclerosis, Thrombosis, and Vascular Biology 200728 27-38.

2 Schindhelm RK, Diamant M, Dekker JM, Tushuizen ME, Teerlink T \& Heine RJ. Alanine aminotransferase as a marker of nonalcoholic fatty liver disease in relation to type 2 diabetes mellitus and cardiovascular disease. Diabetes/Metabolism Research and Reviews 200622 437-443.

3 Porte D. Clinical importance of insulin secretion and its interaction with insulin resistance in the treatment of type 2 diabetes mellitus and its complications. Diabetes/Metabolism Research and Reviews 200117 181-188.

4 Prentki M \& Nolan CJ. Islet $\beta$ cell failure in type 2 diabetes. Journal of Clinical Investigation 2006116 1802-1812.

5 Weyer C, Bogardus C, Mott DM \& Pratley RE. The natural history of insulin secretory dysfunction and insulin resistance in the pathogenesis of type 2 diabetes mellitus. Journal of Clinical Investigation $1999 \mathbf{1 0 4} 787-794$.

6 Ferrannini E, Balkau B, Coppack SW, Dekker J, Mari A, Nolan J, Walker M, Natali A, Beck-Nielsen H \& the RISC Investigators, . Insulin resistance, insulin response, and obesity as indicators of metabolic risk. Journal of Clinical Endocrinology and Metabolism $2007922885-2892$.

7 Tushuizen ME, Bunck MC, Pouwels PJ, Bontemps S, Van Waesberghe JH, Mari A, Heine RJ \& Diamant M. Pancreatic fat content and $\beta$-cell function in men with and without type 2 diabetes. Diabetes Care $2007302916-2921$.

8 Wagenknecht LE, Langefeld CD, Scherzinger AL, Norris JM, Haffner SM, Saad MF \& Bergman RN. Insulin sensitivity, insulin secretion, and abdominal fat: the Insulin Resistance Atherosclerosis Study (IRAS) Family Study. Diabetes 200352 2490-2496.

9 Utzschneider KM, Carr DB, Hull RL, Kodama K, Shofer JB, Retzlaff BM, Knopp RH \& Kahn SE. Impact of intra-abdominal fat and age on insulin sensitivity and beta cell function. Diabetes 2004 53 2867-2872.

10 Gastaldelli A, Sironi AM, Ciociaro D, Positano V, Buzzigoli E, Giannessi D, Lombardi M, Mari A \& Ferrannini E. Visceral fat and beta cell function in non-diabetic humans. Diabetologia $2005 \mathbf{4 8}$ 2090-2096.

11 McManus RM, Cunningham I, Watson A, Harker L \& Finegood DT. Beta-cell function and visceral fat in lactating women with a history of gestational diabetes. Metabolism 2001 50 715-719.

12 Sironi AM, Gastaldelli A, Mari A, Ciociaro D, Positano V, Buzzigoli E, Ghione S, Turchi S, Lombardi M \& Ferrannini E. Visceral fat in hypertension: influence on insulin resistance and beta-cell function. Hypertension $2004 \mathbf{4 4} 127-133$.

13 Kahn SE, Hull RL \& Utzschneider KM. Mechanisms linking obesity to insulin resistance and type 2 diabetes. Nature $2006 \mathbf{4 4 4}$ 840-846.

14 Mari A, Schmitz O, Gastaldelli A, Oestergaard T, Nyholm B \& Ferrannini E. Meal and oral glucose tests for assessment of beta-cell function: modeling analysis in normal subjects. American Journal of Physiology. Endocrinology and Metabolism $2002 \mathbf{2 8 3}$ E1159-E1166.

15 Pacini G \& Mari A. Methods for clinical assessment of insulin sensitivity and beta-cell function. Best Practice and Research. Clinical Endocrinology and Metabolism 200317 305-322.

16 Provencher SW. Estimation of metabolite concentrations from localized in vivo proton NMR spectra. Magnetic Resonance in Medicine $199330672-679$.

17 Elbers JM, Haumann G, Asscheman H, Seidell JC \& Gooren LJ. Reproducibility of fat area measurements in young, non-obese subjects by computerized analysis of magnetic resonance images. International Journal of Obesity and Related Metabolic Disorders 1997 21 1121-1129.

18 Van Cauter E, Mestrez F, Sturis J \& Polonsky KS. Estimation of insulin secretion rates from C-peptide levels. Comparison of individual and standard kinetic parameters for C-peptide clearance. Diabetes $1992 \mathbf{4 1} 368-377$.

19 Levy JC, Matthews DR \& Hermans MP. Correct homeostasis model assessment (HOMA) evaluation uses the computer program. Diabetes Care 199821 2191-2192.

20 Mari A, Pacini G, Murphy E, Ludvik B \& Nolan JJ. A model-based method for assessing insulin sensitivity from the oral glucose tolerance test. Diabetes Care 200124 539-548.

21 Nathan DM, Davidson MB, DeFronzo RA, Heine RJ, Henry RR, Pratley R \& Zinman B. American Diabetes Association. Impaired fasting glucose and impaired glucose tolerance: implications for care. Diabetes Care 200730 753-759.

22 Camastra S, Manco M, Mari A, Baldi S, Gastaldelli A, Greco AV, Mingrone G \& Ferrannini E. Beta-cell function in morbidly obese subjects during free living: long-term effects of weight loss. Diabetes $2005542382-2389$.

23 Carr DB, Utzschneider KM, Boyko EJ, Asberry PJ, Hull RL, Kodama K, Callahan HS, Matthys CC, Leonetti DL, Schwartz RS, Kahn SE \& Fujimoto WY. A reduced-fat diet and aerobic exercise in Japanese Americans with impaired glucose tolerance decreases intra-abdominal fat and improves insulin sensitivity but not $\beta$-cell function. Diabetes $2005 \mathbf{5 4} 340-347$.

24 Tiikkainen M, Bergholm R, Vehkavaara S, Rissanen A, Hakkinen AM, Tamminen M, Teramo K \& Yki-Jarvinen H. Effects of identical weight loss on body composition and features of insulin resistance in obese women with high and low liver fat content. Diabetes 200352 701-707.

25 Greenberg AS \& McDaniel ML. Identifying the links between obesity, insulin resistance and beta-cell function: potential role of adipocyte-derived cytokines in the pathogenesis of type 2 diabetes. European Journal of Clinical Investigation 200232 (Suppl 3) 24-34.

$26 \mathrm{Hu}$ FB, Meigs JB, Li TY, Rifai N \& Manson JE. Inflammatory markers and risk of developing type 2 diabetes in women. Diabetes 200453 693-700.

27 Krakoff J, Funahashi T, Stehouwer CD, Schalkwijk CG, Tanaka S, Matsuzawa Y, Kobes S, Tataranni PA, Hanson RL, Knowler WC \& Lindsay RS. Inflammatory markers, adiponectin, and risk of type 2 diabetes in the Pima Indian. Diabetes Care 200326 1745-1751.

28 Vozarova B, Stefan N, Lindsay RS, Saremi A, Pratley RE, Bogardus C \& Tataranni PA. High alanine aminotransferase is associated with decreased hepatic insulin sensitivity and predicts the development of type 2 diabetes. Diabetes $2002 \mathbf{5 1}$ 1189-1895.

29 Hanley AJ, Williams K, Festa A, Wagenknecht LE, D'Agostino RB Jr, Kempf J, Zinman B \& Haffner SM. Elevations in markers of liver injury and risk of type 2 diabetes: the Insulin Resistance Atherosclerosis Study. Diabetes 200453 2623-2632.

30 Sattar N, Scherbakova O, Ford I, O’Reilly DS, Stanley A, Forrest E, Macfarlane PW, Packard CJ, Cobbe SM \& Shepherd J. Elevated alanine aminotransferase predicts new-onset type 2 diabetes independently of classical risk factors, metabolic syndrome, and C-reactive protein in the West of Scotland Coronary Prevention Study. Diabetes $2004532855-2860$. 
31 Schindhelm RK, Dekker JM, Nijpels G, Heine RJ \& Diamant M. No independent association of alanine aminotransferase with risk of future type 2 diabetes in the Hoorn Study. Diabetes Care 2005282812.

32 Nannipieri M, Gonzalez C, Baldi S, Posadas R, Williams K, Haffner SM, Stern MP \& Ferrannini E. Liver enzymes, the metabolic syndrome and incident diabetes: the Mexico City Diabetes Study. Diabetes Care 200528 1757-1762.

33 Westerbacka J, Kolak M, Kiviluoto T, Arkkila P, Sirén J, Hamsten A, Fisher RM \& Yki-Jarvinen H. Genes involved in fatty acid partitioning and binding, lipolysis, monocyte/macrophage recruitment, and inflammation are overexpressed in the human fatty liver of insulin-resistant subjects. Diabetes $2007 \mathbf{5 6}$ 2759-2765.

Received 1 June 2008

Accepted 14 June 2008 